\title{
O que é "ser adulto": as práticas e representações sociais sobre o que é "ser adulto" na sociedade portuguesa
}

\author{
Filomena Carvalho Sousa
}

\section{RESUMO}

Este artigo refere-se ao trabalho de investigação desenvolvido no âmbito do doutoramento em Sociologia do Instituto Superior de Ciências do Trabalho e da Empresa (ISCTE), Lisboa - Portugal, tese que pretende identificar e caracterizar as práticas e as representações sociais sobre o que é "ser adulto" na sociedade portuguesa.

Nesta pesquisa apresenta-se um modelo de análise e discussão que se assenta na representação de ser adulto, de acordo com duas diferentes concepções:

1- Representação hegemónica - $\mathrm{O}$ adulto é um estatuto a atingir com a obtenção de estabilidade na vida profissional, financeira e familiar. Contudo, considera-se que esta é uma representação que não se coaduna com a realidade das actuais trajectórias complexas, múltiplas e destandardizadas. 2- Representação emancipada - Representação que já não se apresenta como hegemônica, mas sim como restrita a alguns jovens adultos/adultos da classe média/média alta urbana. Substitui o carácter pejorativo e estático do conceito de adulto pelo conceito de adulto, que implica a idéia de aprendizagem contínua, de autorealização pessoal, profissional e afectiva, segundo o qual a evolução se dá de acordo com percursos complexos de avanços e recuos (MACHADO PAIS, 2001). Um adulto como perene aprendiz que comunica e, dominando e exercitando a língua portuguesa falada ou escrita, conta-se e estrutura-se na construção da sua autobiografia.

Palavras-chave: adultez, adulto inacabado, adulto padrão e sociologia do adulto.

\section{Título em inglês: WHAT IT IS TO BE AN ADULT IN PORTUGUESE SOCIETY?}

\section{ABSTRACT}

This article refers to the research work that identifies and characterise the social representations of what it is to be an adult in Portuguese society.

The analysis model presented in this research is based on the representation of being an adult according to two different conceptions:1- Hegemonic representation - The adult is a status attained with the realisation of stability in professional, financial and family life. However, it is considered that this is a representation that does not relate to the reality of the actual complex, multiple and destandardised life-course. 2- Emancipated Representation - Representation that is not anymore presented as hegemonic but as restricted to some young adults/adults of the urban upper-middle/middle classes. It replaces the negative and static character concept of an adult, with the adult concept that implies the idea of continuous learning, personal, professional and sentimental auto-accomplishment and according to which evolution is achieved in accordance with the complex passages of (advances and set-backs).

Idex terms: "adultez", inconcluded adult, standard adult, Sociology of Adult 


\section{Introdução}

O interesse por esta investigação surge depois do trabalho de pesquisa realizado sobre a transição dos jovens para a vida adulta; do contacto directo com jovens e jovens adultos, enquanto docente do ensino superior e responsável pelo departamento da juventude numa câmara municipal e do relacionamento com adultos - enquanto formadora de adultos, profissional e avaliadora externa de processos de reconhecimento e validação de competência de adultos, em centros de estudo em que os adultos podem adquirir a escolaridade obrigatória, $9^{\circ}$ ano, através do reconhecimento de competências pessoais, familiares, sociais e profissionais. Essas experiências encaminharam-me para determinadas questões: 1- Como se pode entender os modelos de transição para uma determinada fase de vida, se não existe investigação acerca dessa mesma fase de vida, ou seja, a vida adulta? Como posso estudar a forma pela qual se transita para uma determinada fase de vida, se não se sabe o que ela significa? 2- De que modo se socializa para ser adulto? 3- A escola e a família socializam os jovens para um adulto que se enquadra na actual realidade social? Que adulto é esse? Ou seja: Afinal, o que é "ser adulto" na sociedade portuguesa?

A verdade é que, quando se pretende realizar uma pesquisa acerca das práticas e representações sociais sobre o que é "ser adulto", encontra-se, de imediato, uma lacuna da investigação social em relação a esta fase de vida. Isto porque, com alguma facilidade se encontra uma extensa bibliografia sobre questões ligadas à infância, à adolescência, à juventude e ao idoso; o mesmo não se passa quando se pretende trabalhar em torno do conceito de adulto. Conceitos como adultez, adulteidade e adultecência são relativamente recentes e revelam a necessidade de conceptualização da temática; e ainda, demonstram a pertinência, a importância e a actualidade do estudo acerca do Adulto.

Mas, por que são tão raros os estudos sociológicos sobre a adultez?

De acordo com Boutinet (2000), na sua obra $A$ imaturidade da vida adulta, os estudos sobre o adulto são, na generalidade, escassos porque "falar sobre a vida adulta pode parecer aparentemente banal" (BOUTINET, 2000, p. 13); a vida adulta é "deixada aparentemente nas suas antigas certezas como uma idade sem problemas, uma vez definida como idade de referência" (BOUTINET, 2000, p. 11) para todas as outras fases de vida. Destacamos esta afirmação de Boutinet já que ela nos remete para a particular atenção que se deve dar à vida adulta e provoca algumas interrogações: para além da aparência, a vida adulta pode ser outra coisa que não uma idade de referência? A que "antigas certezas" se está a referir Boutinet? Será que, nos dias de hoje, podemos referir-nos à adultez como 
uma fase de vida aproblemática? Não será evidente a sua complexidade? Parece cada vez mais inegável a importância de considerar a idade adulta enquanto objecto teórico e de investigação e, para além do défice conceptual com que nos confrontamos quando se pretende pesquisar sobre esta fase de vida, a temática da idade adulta torna-se cada vez mais actual. A provar isso estão os mais variados termos que surgem na língua portuguesa e tentam definir a fase de vida adulta, como, por exemplo, adultez, "adultado, adultidade, adultescência, andragogia, maturescência, antropolescência" (BOUTINET, 2000; COSTA E SILVA, 2003), e ainda, vocábulos que evidenciam a indeterminação dos limites das categorias etárias e a ambivalência complexa e paradoxal que envolve o conceito de vida adulta (BOUTINET, 1993).

Esta ambiguidade tem vindo a ser tema de interesse, a partir dos anos de 1990, de um maior número de estudiosos devido, especialmente, ao facto do modelo tradicional de entrada na vida adulta, que considera o adulto como um estatuto a atingir com a obtenção de estabilidade na vida profissional, financeira e familiar, sofrer várias pressões sociais com: a- O prolongamento escolar e a necessidade de formação contínua; b- O crescimento de aspirações à mobilidade social; c- A mudança no sistema familiar e matrimonial - os novos modelos conjugais; d- A possibilidade de se programar e adiar o momento da procriação - que permite maior autonomia na gestão dos calendários profissionais, escolares, conjugais e de lazer; e- A melhoria das condições de vida - saúde e higiene tendo o adulto a possibilidade de viver mais anos, remetendo a idéia de morte para lá de um percurso que se prolonga por uma diversidade de experiências de vida; o aumento da esperança de vida permite questionar o momento em que se deve ou pretende "assentar" e, neste caso, estabilidade pode significar não evoluir num percurso aberto a múltiplas possibilidades; f- As mudanças nos modos de passagem à vida profissional, os quais, cada vez mais longos, conduzem menos frequentemente e menos directamente a um emprego estável; g- A revolução das necessidades, o incremento do consumo, da informação, da promoção do lazer, do "rejuvenescimento" e do hedonismo (TEIXEIRA, 2001).

O factor social mais importante na idade adulta sobre o qual devemos reter a nossa atenção é, no fundo, o desenvolvimento de uma sociedade assente numa cultura pósmoderna: a idade adulta deixou de ser aproblemática e remetida para segundo plano, pois segundo Boutinet (2000), já não se estrutura como a idade da referência e da norma. A fase de vida adulta, com o aumento da esperança de vida, ocupa cerca de trinta e cinco a quarenta anos do total do percurso de vida de cada indivíduo. Este facto torna urgente a 
investigação acerca deste novo adulto que tem pela frente diversos caminhos a percorrer, muitas decisões a tomar e experiências para viver.

$\mathrm{Na}$ actualidade, a idade adulta é uma idade de inacabamento, autonomia, liberdade, incerteza, risco e individualização (BOUTINET, 2000). Por outro lado, o adulto inacabado da modernidade avançada coexiste com o adulto padrão da modernidade e estabelece-se um paradoxo particular entre a representação tradicional e a representação moderna (positivista ou pessimista) do que é ser adulto. Os valores pós-modernos caracterizam uma sociedade em que se questionam as evidências, onde os adultos pensam a sua existência num cenário de dilemas, de oposições e de dialéctica, onde a pessoa e as instituições têm de reinventar-se constantemente. Há que se pontuar que nessas circunstâncias, o domínio da língua portuguesa, escrita e falada, permite ao indivíduo posicionar-se na envolvente e complexa vida social, já que estas habilidades facilitam o exercício quotidiano de reflexividade, o questionamento dos problemas e das oportunidades e a tomada de decisões.

É, então, urgente realçar os paradoxos que se evidenciam entre estas duas representações de ser adulto e estruturar um quadro teórico para a adultez. A pertinência da questão $O$ que é ser adulto? justifica-se com a necessidade de trabalhar uma fase de vida a qual não pode ser ignorada e que, tendo sido considerada como referência para outras idades, aparece agora desestabilizada. Ignorar a existência de um número cada vez maior de adultos desiludidos ou resignados com o seu trabalho e com a sua vida familiar é fechar os olhos a uma realidade que leva adolescentes, jovens e os próprios adultos a afirmarem que não querem ser adultos e a adoptarem uma postura pessimista face à adultez.

Perante a complexidade da questão opta-se, invariavelmente, pelo discurso mais negativo permeado por uma certa nostalgia pelo passado e pela rejeição da actualidade, não se assumindo as contradições, condição que, segundo Boutinet (2000) diminui a possibilidade de se viver os paradoxos não como problemas mas como estruturantes. Como foi referido, é verdade que o novo adulto tem de lidar com as premissas de duas diferentes épocas sociais - a modernidade e uma nova modernidade avançada. Contudo, essa complexidade não deve ser entendida apenas de acordo com a perspectiva de crise; o importante é entendê-la na diversidade e heterogeneidade de modelos de adultez, que deve ser inventariada, analisada e interpretada. O "medo de ser adulto" pode dar-se, exactamente, porque se desconhece o que significa, nos dias de hoje, viver nesta fase de vida. Sabe-se que muita coisa mudou, mas não se compreende em que sentido. Talvez esta 
pesquisa possa surgir como precursora de uma Sociologia do Adulto $^{1}$ em Portugal e contribua para o desenvolvimento de teorias que evidenciem a necessidade de se identificar formas de viver a adultez, contribuindo para potenciar as possibilidades da vida social do adulto na nova modernidade. O desenvolvimento da Sociologia do Adulto promove, ainda, novas perspectivas de investigação para o estudo da juventude, da transição para a vida adulta e do idoso. Importa, ainda, expor mais alguns argumentos em defesa da necessidade e pertinência da construção de uma Sociologia do Adulto. Isto porque, num primeiro momento, defender a imputação de um campo específico da Sociologia a esta fase de vida parece suscitar, recorrentemente, a opinião de que o adulto já é estudado em áreas bem balizadas e consolidadas como a Sociologia da Família, a Sociologia do Trabalho, a Sociologia da Educação ou do Lazer. Todavia, este raciocínio é rapidamente refutado se tomarmos como exemplo a naturalidade com que se reconhece a importância da Sociologia da Juventude ou do Idoso. Também em relação a estas duas fases de vida se estuda, usualmente, a forma como os jovens ou os idosos vivem e são entendidos, por exemplo, na família e no trabalho; contudo, isso não invalida a existência de um campo da Sociologia que se dedique exclusivamente a eles.

O estudo da vida adulta encontra-se inscrito na bruma e na marginalidade. Isso porque é necessário um exercício de desconstrução para conceber o adulto fora da sua "normalidade" ou mesmo da sua "banalidade". Esse exercício implica a autoconfrontação e o balanço entre aquilo que é socialmente correcto, normalizado, o que é socialmente imposto, o que é socialmente proporcionado e possibilitado, e ainda, aquilo que se pensa, o que se quer, as ambições, as acções, os trajectos e as estratégias definidas individualmente.

\section{Do adulto padrão ao adulto perspectiva ou problema}

$\mathrm{O}$ adulto padrão define-se como o indivíduo equilibrado, estável, instalado e, consequentemente, rotineiro. Trata-se de um adulto produto da confiança ilimitada no progresso, na possibilidade de se poder controlar e projectar todas as dimensões da vida humana através da definição de um ciclo de vida linear, com etapas a percorrer e objectivos a cumprir. $\mathrm{O}$ adulto padrão será aquele que atingiu a maturidade biológica, sexual, psicológica. Ou seja, conforme Boutinet (2000), identidade social construída, na

\footnotetext{
${ }^{1}$ Não existe qualquer incompatibilidade ou sobreposição nos interesses dessas diferentes áreas de estudo. Todas têm as suas especificidades e os objectos de pesquisa próprios. Conquanto o adulto é parte integrante da população estudada pela Sociologia da Família ou do Trabalho, em relação a um qualquer tema; a família e o trabalho serão dimensões do estudo da Sociologia do Adulto. Ou seja, a perspectiva com que se avança para a investigação é diferente, as questões que se colocam são diversas e os resultados, para além de complementares, distintos.
} 
perspectiva da inserção e da autonomia financeira. Um estatuto, o qual não pode ser definido exclusivamente em termos etários, mas que, usualmente, é remetido para uma idade que se encontra entre o intervalo dos 25 aos 65 anos.

Nesse caso, referimo-nos a um conceito integrado num modelo de sociedade masculino, do adulto viril, chefe de família e inserido profissionalmente.

Após a Segunda Grande Guerra e, sobretudo, nos anos 60 e 70 do século XX, o termo adulto adquire novos significados. Considerando concepções provenientes da Psicologia, da Psiquiatria e da Filosofia é possível identificar o desenvolvimento de várias pesquisas (TEIHLARD DE CHARDIN, 1959; ROGERS, 1961; LAPASSADE, 1963) que têm em conta as mudanças socio-económicas advindas de uma sociedade industrial em expansão; o desenvolvimento e impacto de novos dispositivos técnicos e das novas tecnologias da informação; o incremento da sociedade de consumo e a evidência do fenómeno da individualização. Desse modo, substitui-se o adulto padrão - como estado terminado e estático - pelo "adulto inacabado", sujeito a um contínuo processo de construção e desenvolvimento. O adulto "é entendido doravante [...] (em) maturidade vocacional nunca atingida, (...) em contínua conquista" (BOUTINET, 2000, p. 17). Dito de outro modo, um adulto como perene aprendiz que tem de dominar e aperfeiçoar as suas competências de oralidade, da escrita e da língua com que se expressa no meio social.

Perante esta nova direcção dada à definição do conceito de adulto é possível identificar duas posições distintas. Assim, se por um lado se identifica o adulto com um processo de construção, questiona-se o sentido desse processo e, até meados dos anos 70, vários trabalhos defendem, essencialmente, a perspectiva do optimismo construtivista uma corrente assente na perspectiva humanista evolucionista (ROGERS, 1961), que fundamentava a existência de uma orientação positiva para todos os homens. O "estado inacabado do homem" era visto como a possibilidade de progredir e de conservar as suas formas juvenis. Nesse caso, a angústia dos indivíduos face às características da sociedade moderna e industrial é considerada como "remanescente, como portadora de esperanças e optimismo" (BOUTINET, 2000, p. 15). Nos anos 60-70, o recurso à mudança é, então, proclamado por um "optimismo ingénuo" que origina alguns efeitos perversos. O "medo de mudar" é entendido como "resistência à mudança" e é visível a obsessão pela dinâmica dos percursos e dos acontecimentos.

A partir dos anos 90, o processo de construção ao qual o adulto está sujeito passa a ser questionado segundo uma visão pessimista; a angústia deixa de ser considerada como remanescente, para colocar o adulto perante uma situação, por vezes, desesperante. $\mathrm{O}$ 
desenvolvimento de uma sociedade pós-industrial - na qual predomina a incerteza, o risco ${ }^{2}$, as desordens, as situações de precariedade, além da vulnerabilidade e da marginalização promove a permanente instabilidade, especificamente, no trabalho e na família (BOUTINET, 2000; EHERENBERG, 1991, 1995)³.

Jean-Pierre Boutinet (2000) lista, assim, três modelos que estão na base da definição do conceito de adulto: 1) um modelo tradicional do adulto padrão, estático, estável, que caminha, vocacionalmente, para uma maturidade que entende como definitiva - modelo que se considera ainda persistir como representação predominante na sociedade portuguesa - e outros dois modelos emergentes que, nos últimos trinta anos, têm caracterizado as duas direcções para onde se encaminha o adulto inacabado. São eles: 2) o adulto em perspectiva, do perene desenvolvimento vocacional; e 3) o adulto como problema, do caos vocacional ${ }^{4}$.

\section{O novo adulto - o inacabamento coexiste com a padronização}

O que consideramos perante essas definições do conceito de adulto é que todas elas coexistem actualmente no próprio indivíduo e na sua forma de viver a adultez. Estabelecese um paradoxo particular entre a representação tradicional e a representação moderna (optimista ou pessimista) do que é ser adulto. Verifica-se um dualismo que caracteriza a sociedade portuguesa em sua caminhada para uma nova modernidade: a existência de "mudança na continuidade" e a "continuidade na mudança" (MACHADO PAIS, 2001; COSTA E SILVA, 2003). A “prematuração e a imaturidade coexistem ao mesmo nível que peças da sociedade industrial perduram dentro da sociedade pós-industrial" (BOUTINET, 2000, p. 228).

Ou seja, como se afirma anteriormente, a representação do adulto continua a imporse numa perspectiva de estabilidade - o adulto socialmente inserido e categoria etária de referência para as demais categorias etárias - no entanto, o indivíduo, pressionado ou de forma voluntária, procura afastar-se dessa impressão de estabilidade. “Actuais testemunhos

\footnotetext{
2 "Não que a modernidade seja mais arriscada do que épocas anteriores [...], o que é novo é a inevitabilidade do raciocínio em termos de avaliação desses riscos" (TEIXEIRA, 2001; p. 37; GIDDENS, 2000).

3 A exemplo da corrente que entende o adulto como problema, Boutinet (2000) refere-se à obra de A. Ehrenberg, L'individu incertain (1995), em que se evidencia o facto de o adulto se interrogar constantemente sobre o lugar que ocupa na sociedade, os papéis e as tarefas que desempenha, o que leva Ehrenberg a afirmar que nos encontramos na idade do indivíduo inseguro, pois, mesmo quando não se está socialmente excluído, a possibilidade, a ameaça de tal acontecer está sempre presente.

${ }_{4}$ Por caos vocacional entende-se a extrema sensibilidade das trajectórias existenciais às rupturas e às desestabilizações: a incapacidade de prever ou projectar o futuro e a dificuldade em gerir de modo referenciado situações de crise. E, se os acontecimentos destabilizadores nem sempre promovem situações totalmente perigosas ou aleatórias, pois as determinações próprias do adulto e o confronto com situações-limite podem deixar antever, em profundidade, uma nova estruturação, uma nova vida e novas oportunidades, existe sempre a impressão de que a situação é caótica (BOUTINET, 2000).
} 
de adultos evidenciam a sua preocupação de se manterem jovens o máximo tempo possível, até mesmo adolescentes, nunca deixarem de crescer, mantendo-se neoténicos (inacabados), sempre em busca de realizações a completar, de acções a recomeçar com a preocupação de conservar uma réstia de juventude, um gosto permanente do inédito." (BOUTINET, 2000, p. 19). Porém, ao assegurar cada vez menos a sua identificação a um estatuto de estabilidade, o adulto vê-se ele próprio sem pontos de referência, por vezes perdido entre múltiplas dependências. Vê-se vulnerável, confrontado com situações complexas que o ultrapassam.

$\mathrm{O}$ adulto situa-se actualmente numa sociedade de escolhas, decisões e de projectos. ${ }^{5}$ Contudo, essas decisões, escolhas e esses projectos realizam-se cada vez mais sem a protecção de um quadro estruturado de identificações; cada vez mais as decisões dependem do indivíduo e da sua capacidade de se auscultar a si próprio. A sensação é, por vezes, a de “duplo vazio existencial e societal" (BOUTINET, 2000, p. 227).

Existem, dessa forma, duas lógicas que resumem as diversas perspectivas sobre o que é ser adulto: a primeira, considera o adulto um sujeito equilibrado, estável, mesmo rotineiro e instalado e outra, que reconhece o adulto como um sujeito que se perspectiva em desenvolvimento, numa atitude de experimentação, de progressão, de formulação de desejos e concretização de projectos (COSTA E SILVA, 2003) e outra que trata o adulto como aquele que tem que lidar com o imprevisto, o risco, a exclusão e a inexistência de quadros de referência.

Essas duas lógicas que se opõem e conferem ao adulto uma definição paradoxal, também se podem unir, "produzindo um efeito desmultiplicador numa espécie de desestabilização" (BOUTINET, 2000, p. 19) e simultaneamente, de potencialização da vida adulta, estando o desafio na capacidade de ser reflexivo, e de fazer balanços, de forma a "agarrar" as oportunidades quando elas surgem, ou desistir de projectos condenados ao insucesso (GIDDENS, 2000).

\section{Os extremos - da sublimação à morte do adulto}

Para além da dualidade adulto padrão/adulto inacabado, a representação social sobre o que é "ser adulto" enquadra-se, usualmente, entre duas representações antagônicas: uma que sobrevaloriza a adultez e outra que a desvaloriza completamente; ou seja, uma representação positiva e outra negativa.

\footnotetext{
${ }^{5}$ Projectos em diferentes âmbitos: profissionais, de carreira, familiares, de orientação, inserção, formação, de reforma, entre outros.
} 
A imagem da adultez enquanto fase de aquisição de estabilidade, idade de referência e fase da concretização das ambições e projectos definidos na vida familiar e profissional; parece ter sido, até há cerca de trinta anos, algo inquestionável e que remetia o adulto para um pedestal em relação às outras fases de vida, isto considerando a sua capacidade de realização pessoal e o valor da sua utilidade social e produtiva.

A adultez é entendida, nesse sentido, como um estatuto a atingir pelos mais jovens e a recordar com nostalgia pelos mais velhos. É esta fase de vida que estrutura a definição do ciclo de vida do indivíduo, pois é nela que ele, o adulto, se evidencia, projecta e realiza. Essa definição de adulto idealiza um indivíduo perfeito que é sublime, um herói, um santo, o empresário de sucesso, competente e vencedor (BOUTINET, 2000). A questão que se coloca é se essa representação de adulto continua ser actual? Se ela se ajusta a uma sociedade cada vez menos previsível e cada vez mais incerta? Ou mesmo, se este adulto exemplar alguma vez existiu na prática?

O que acontece, na maior parte das vezes, é verificar-se um movimento entre um “optimismo utópico e um pessimismo exagerado", entre a exaltação e a depressão de ser adulto (MILLET-BARTOLI, 2002; BOUTINET, 2000), entre a "sublimação", que coloca o adulto no primeiro lugar do pódio das fases de vida (enaltecendo a plenitude das capacidades físicas e psicológicas e a possibilidade de total realização e reconhecimento pessoal e social) e a recusa da aquisição de tal estatuto, promovendo-se a teoria da "morte ou inexistência" desse adulto ideal-tipo - enumerando as desvantagens de ser adulto: os sinais de envelhecimento, de cansaço e de desgaste físico e psicológico. Entre essas duas posições é usual, ainda, a atitude, não menos negativa, de resignação ou indiferença.

Para A. Miranda Santos, no artigo A inexistência da adultez (1979), o adulto é apenas um modelo referencial, teórico, ideal que nunca existiu em termos reais. Miranda Santos vê este adulto como "uma pobre imagem que, provavelmente, se forma e conserva em nós desde a infância e, por isso, comporta numerosos elementos inconscientes. Como imagem é uma realidade. Mas, perante a realidade, obtida ou a obter por observação científica, é apenas uma ilusão" (SANTOS, 1979, p. 144).

Para Santos, na obra utilizada acima, esse é um "modelo metafísico-moralizante do adulto" que tem por base "a famosa e por demais arreigada divisão, quer em psicofisiologia, quer em psicopatologia, ou seja, [...] da existência em evoluçãoinvolução" (SANTOS, 1979, p. 146).

Por outro lado, será alguma vez possível falar da perfeição e do acabamento total, do fim do crescimento ou da maturidade plena? Até porque só a ausência de perfeição total 
será um sinal da possibilidade da perfeição (SANTOS, 1979; BOUTINET, 2000; COSTA E SILVA, 2003).

Considerando a relação que se estabelece entre a importância dada a esta fase de vida e aos outros momentos da mesa, Miranda Santos afirma que este adulto ideal-tipo

[...] implica a afirmação dum modelo-exemplar, por referência ao qual tudo o resto é julgado ou apreciado, ou mais ou menos perfeito ou em vias de perfeição ou de perda. A criança admira e tenta aproximar-se, outros diriam «imitar» e outros ainda «identificar-se»; o adolescente continua a atribuir todo um fascínio ao modelo ou, em alguns sectores e em certos casos hoje, um repúdio ou rejeição muito curiosos [...]; o adulto-homem, pode declarar, com uma faceta de esnobismo ou de pena, que ainda lá não chegou; a mulher adulta ou nunca se sentia verdadeiramente ela própria porque o modelo lhe é inacessível ou tentará encontrar modo de o conquistar - individualmente ou em grupo; o velho, enfim, lamentará ter perdido ou nunca ter atingido esse estado considerado de cimo ou máximo de perfeição (SANTOS, 1979, p. 143).

Partir do pressuposto da inexistência do adulto foi, no entanto, para esse autor, uma forma de provocar para que se prove o contrário e, como se referiu anteriormente, para que se avance para a pesquisa da adultez e se encontre e estude esse ou outros modelos de adulto, não na perspectiva puramente teórica, filosófica ou literária, mas assumindo a importância do desenvolvimento do trabalho empírico dentro de uma perspectiva psicossociológica.

Outro argumento que induz à hipótese da morte do adulto tem a ver com o facto de ser cada vez mais difícil delimitar as diferentes fases da vida, em termos etários, das práticas, dos comportamentos e das atitudes que mais correspondem conformes às mesmas. Estas vão diluindo-se umas nas outras e deixam ao adulto um espaço que parece cada vez mais curto e indefinido. Na verdade, se, por um lado, a juventude prolonga-se por tempos de experimentação, percursos escolares e papéis sociais, por outro lado, o adulto e o idoso parecem rejuvenescer.

Ou seja, os jovens são um género de "social no man's land" (BOURDIEU, 1984, p. 95) - são adultos para certas coisas e para outras não, ou então, é-se jovem e adulto em simultâneo (RAMOS, 2002), daí resulta a ambígua expressão jovens adultos a testemunhar a mudança que actualmente define o prolongamento do período de transição para a vida adulta. $\mathrm{O}$ indivíduo situa-se numa posição intermédia: já não se considera propriamente jovem, mas também não se acha adulto; está numa fase híbrida entre o ser jovem e o ser adulto, fase de é recém-adulto. 
Por sua vez, a seguir ao jovem adulto poder-se-ia identificar o indivíduo que se caracteriza como adulto-jovem, aquele que se referencia cada vez mais na juventude. Torna-se óbvia a tendência das gerações mais velhas para adquirir atitudes e práticas anteriormente pertencentes apenas à juventude: modos de vestir, práticas de lazer e consumo, linguagem, valorização do corpo e de uma nova ética de vida, de trabalho, de família e de lazer. A atracção pela aventura e pelo risco já não caracteriza apenas os comportamentos das gerações mais jovens, ela é parte integrante da sociedade contemporânea (MACHADO PAIS, 2001). Nesse sentido, quase se poderia defender a reformulação do conceito de adulto ou mesmo da substituição deste estatuto e fase de vida nas sub-fases de jovem adulto e adulto jovem. Principalmente, quando, mesmo perante o envelhecimento da população, o idoso começa a perspectivar-se como um novo idoso, quer dizer, um idoso que é cada vez mais sensibilizado para a necessidade de promover um estilo de vida saudável, fazer dietas, fazer exercício físico e manter-se activo.

Referenciado na juventude e neste jovem idoso, também o adulto, sabendo, à partida, que a sua vida se poderá prolongar ainda por várias décadas, preserva-se e promove práticas de rejuvenescimento. Esse facto leva a que, cada vez mais, se distinga a idade cronológica da idade funcional e o adulto jovem começa a comportar-se cada vez menos de acordo com o estereótipo definido para as pessoas que têm, por exemplo, entre os 35 anos e os 45 anos, pois a sua performance física e o seu desempenho intelectual são maiores do que do que o esperado. A esse fenómeno alguns autores chamam de youth creep (rejuvenescimento), isto é, a idade funcional dos indivíduos torna-se mais jovem que a idade cronológica, e pessoas com 65 anos comportam-se de acordo com o que era o comportamento típico das pessoas de 55 anos (jovem idoso), quem tem 55 anos comportase como se tivesse 45 e assim sucessivamente até à idade do jovem adulto - mais activos, mais saudáveis e com uma aparência mais cuidada e jovem (LEMME, 1995). Ou seja, de jovem passa-se para jovem adulto, depois para adulto jovem, depois para idoso jovem, depois para idoso e depois para idoso idoso, sem que reste um espaço para o adulto.

Perante esses factos, opta-se, nesta análise, por não defender, contudo, nem a teoria da sublimação do adulto, nem a hipótese da sua morte, e, muito menos, a teoria do seu desaparecimento, da sua diluição enquanto fase de vida em diversas sub-fases. $\mathrm{O}$ adulto existe enquanto categoria etária e social e não pode nem deve ser elevado em relação às demais idades ou estigmatizado pela sociedade em geral. É importante considerar que entre a "resignação construtiva" e o "optimismo trágico" existem muitos compromissos e mundos possíveis. 
Como já foi referido, com o aumento da esperança de vida, a fase da vida adulta corresponde a um período de cerca de trinta a quarenta anos; ora, se fosse possível delimitar as fases de vida de acordo com idades precisas - hipoteticamente e como mero exercício teórico, consideremos que a adultez inicia com a categoria de jovem adulto entre os 25 e os 34 anos - prolongando-se pelo adulto-jovem - dos 35 aos 44 anos - e terminando com a entrada na fase do idoso-jovem aos 65 anos - ainda resta um intervalo entre os 45 e os 64 anos, de cerca de vinte anos, para o "próprio adulto".

Por outro lado, as teorias da inexistência da adultez ou da "morte do adulto" não defendem, verdadeiramente, o desaparecimento dessa fase de vida. Nessas teorias detectase, em particular, o questionamento do modelo ideal-tipo do que é ser adulto - o modelo da estabilidade e da perfeição. Poder-se-á entender essas teorias como provocações que, ao desconstruir a imagem única, sublime, hegemónica da adultez, projectam o interesse para o estudo, nomeadamente da sociologia, sobre essa fase de vida que, cada vez mais, se assume como um objecto de estudo pertinente, diverso e complexo.

Assim, pressupõe-se como bastante provável a existência de muitos indivíduos interessados em saber que a fase de vida em que se encontram "existe" e referencia-se num novo adulto com o qual poderão, ou não, identificar-se. Investigar sobre esse novo adulto será um passo essencial para que se potencie as possibilidades que estão ao dispor do adulto, para que ele se posicione perante uma sociedade complexa e incerta, para que não continue a generalizar-se a representação pejorativa do que é ser adulto e para que diminuam as reacções de "recusa" ou "medo" de ser adulto.

A exaltação do adulto como actor surge com a imposição do planejamento de vida, da escolha e da incerteza, tendo o adulto de agir e tornar-se autónomo em relação a prescrições sociais. Como actor, o adulto tem de assumir uma atitude modesta, aceitando a impossibilidade do total controle sobre a vida e se encontra exposto às diversas circunstâncias da vida. Enquanto actor, o adulto confronta-se com o seu $e u$, valoriza a construção da auto-identidade através da narrativa autobiográfica (BOUTINET, 2000).

Essas biografias referem-se a escolhas realizadas pelos adultos tendo por referência os sistemas abstractos a que têm acesso. Ou seja, a auto-identidade não é algo dado pelas relações sociais estabelecidas, ela é construída, reinventada, interpretada e compreendida pelo próprio indivíduo quando este "se conta", numa narrativa contínua, em termos biográficos.

As narrativas biográficas, influenciadas social e culturalmente, comportam sempre imagens, personagens e "estórias" reinventadas pelo próprio indivíduo. Ou seja, são 
reinvenções que têm como objectivo imprimir continuidade à história de vida, organizar as experiências e dar coerência, significado, a essas experiências. Permitem, ainda, descrever as soluções encontradas para as dificuldades e as tensões provocadas pelos ambientes sociais em que o indivíduo se move. O adulto pode descrever-se em imagens que o caracterizam em diferentes fases do seu percurso, por exemplo, como "o inocente", no início da sua experiência profissional; mais tarde, como "o descrente" e depois como "o revoltado" ou "o vencedor". O adulto reduz a multiplicidade de papéis em "personagens" sumarizadas que unificam experiências e sentimentos. $\mathrm{Na}$ idade adulta muitos desses "personagens" chegam a um ponto máximo da sua auto-expressão e podem ser avaliados, criticados, questionados. Assim, a necessidade da construção da autobiografia advém, na nova modernidade, da importância exaltada à transparência da comunicação e à autenticidade das relações. Neste caso, em relação à autobiografia, o adulto, ao ver suprimidos os quadros de referência e autoridades que enquadravam a sua vida, num exercício de lucidez, envolve-se na sua própria história, no seu passado e nas expectativas que tem em relação ao seu futuro, reapropria-se das suas origens, "fala de si próprio a si mesmo", tenta ser transparente consigo mesmo e decidir sobre seu destino (BOUTINET, 2000).

Para não ser excluído, o adulto deve, perante as diversas esferas sociais, dominar a arte de comunicar e, desse modo, dominar e aperfeiçoar a língua dominante do seu quotidiano. O adulto deve comunicar-se sobre: quem ele é, a sua experiência pessoal, as suas intenções e os seus projectos de vida. Deve conseguir avaliar as suas competências e os seus conhecimentos. A transparência da comunicação sai do gabinete do psicoterapeuta para a praça pública, e assim, é necessário ao adulto contar-se quando vai a uma entrevista de emprego, está na relação íntima, entre o grupo de amigos ou no emprego.

\section{Referências bibliográficas}

BOURDIEU, Pierre. Youth is just a word. In: Sociology in question. London: Sage, 1984, p. 143-155.

BOUTINET, Jean-Pierre. Psychologie de la vie adulte. Paris: PUF, 1993.

A imaturidade da vida adulta. Porto: Rés, 2000.

COSTA E SILVA, Ana Maria. Formação, percursos e identidades. Coimbra: Quarteto, 2003. 
EHRENBERG, A. Le culte de la performance. Paris: Calmann-Lévy, 1991.

L’individu incertain. Paris: Seuil, 1995.

GIDDENS, Anthony. O Mundo na era da globalização. Lisboa: Presença, 2000, p. 1931.

LAPASSADE, G. L'entrée dans Ia vie, essai sur l' inachèvement humain. Paris: De Minuit, 1963.

LEMME, Barbara Hausen. Development in Adulthood. Boston: Allyn and Bacon, 1995, p. 8-12.

MACHADO PAIS, José. Ganchos, tachos e biscates : jovens, trabalho e futuro. Porto: Âmbar, 2001.

MILLET-BARTOLI, Françoise. La crise du milieu de la vie. Paris: Odile Jacob, 2002.

RAMOS, Elsa. Rester enfant, devenir adulte: la cohabitation des étudiants chez leurs parents. Paris: L'Harmattan, 2002.

ROGERS, Carl. Outcoming a person. Houghton Mifflin, 1961.

SANTOS, A. Miranda. A inexistência da Adultez. In: Revista Portuguesa de Pedagogia, v. $13,2^{a}$ série, ano 13,1979 , p. 139-150.

TEIHLARD DE CHARDIN, P. L'avenir de l'homme. Paris: Seuil, 1959.

TEIXEIRA, Elsa Guedes. Solidão, a busca do outro na era do eu: estudo sobre sociabilidade na modernidade tardia. Sociologia Problemas e Práticas, n. 35, 2001, p. 3148.

\section{Autora}

Filomena Carvalho Sousa

Socióloga, Investigadora Convidada do Institut National d'Etudes Démographiques (INED) - Paris

Doutoranda no Instituto Superior de Ciências do Trabalho e da Empresa (ISCTE), Lisboa Portugal

00351918107756

filom_sousa@yahoo.com

\section{Como citar este artigo:}

SOUSA, Filomena Carvalho. O que é "ser adulto": as práticas e representações sociais sobre o que é "ser adulto" na sociedade portuguesa. Revista Moçambras: acolhendo a alfabetização nos países de língua portuguesa, São Paulo, ano 1, n. 2, 2007. Disponível em: <http://www.mocambras.org >. Publicado em: março 2007. 